\title{
Productivity Improvement and Reduction of Lead Time in Manufacturing Industry Using Lean Tools
}

\author{
Sivaraman Parthasarathi", Prabhu M. K., Krishanamani J., Mitun L., Prakash Vellingiri G., \\ Rahul C. S.
}

Mechanical Engineering, Sri Krishna College of Technology, Coimbatore, India

Email address:

sivaraman.p@skct.edu.in (S. Parthasarathi)

${ }^{*}$ Corresponding author

\section{To cite this article:}

Sivaraman Parthasarathi, Prabhu M. K., Krishanamani J., Mitun L., Prakash Vellingiri G., Rahul C. S. Productivity Improvement and Reduction of Lead Time in Manufacturing Industry Using Lean Tools. Industrial Engineering. Vol. 5, No. 1, 2021, pp. 1-6.

doi: $10.11648 /$ j.ie.20210501.11

Received: February 12, 2021; Accepted: February 26, 2021; Published: April 26, 2021

\begin{abstract}
To look at the current arrangement of a creation line in a shop floor of controlling stuff box fabricating industry also, to improve the profitability utilizing lean strategy absent really any influencing current working frameworks. Technique/ Examination: Broad scopes of lean assembling devices are accessible to deal with a wide range of issues looked by changed fabricating businesses. It likewise helps for effective expense decrease of the assembling part and to guarantee the nature of maker and client. Discoveries: The basic Non-Value added Activities (NVA) were perceived and probabilities needed for improvement has been perceived. Value Stream Mapping (VSM) has the standing of finding squander during assembling and business measure which encourage distinguishing and eliminating or stream the worth added steps furthermore, to kill the non-esteem added steps. Application/Improvements: After achievement of fitting lean instruments, it was discovered that the all out arrangement time was consolidated by around 180 minutes and process duration was dense by about 98 minutes which eventually decreases the lead time and builds the efficiency. A lean manufacturing initiative focuses on cost reduction and increases in turnover by systematically and continuously eliminating non-value-added activities. In today's competitive market, lean is turning out to be "the solution" to manufacturing industries across the spectrum for survival and success.
\end{abstract}

Keywords: Lean Manufacturing Tools, Productivity Enhancement, Gear Box, Lead Time, Line Balancing, VSM, Work Standardization

\section{Introduction}

Presently a day's lean assembling method is utilized as a basic vertebral section of the creation framework in producing divisions. Lean assembling has generally been executed in assembling ventures during the most recent thirty years to distinguish the waste and to create recommendations that will take out the equivalent in assembling organizations. The end clients anticipate their assembling sellers/providers to be responsive in conveying items on schedule and consequently, they are constantly inclining towards process duration decrease on the whole the cycles. Process duration is perhaps the main qualities in assembling and it is a time span during which a bunch of back to back activities happens consistently. Thus cycle time is characterized as the hour of longest activity in a sub- assembly and assembly line in a manufacturing industry The process duration will be diminished when the line is adjusted appropriately and subgathering format is enhanced. Lean fabricating has been now actualized in the majority of the huge scope car fabricating businesses. However there has been no data on the execution of lean assembling method in the creation line of medium and limited scope businesses. Because of the high request in the serious market, the makes has to gather in the decrease of process duration during the fabricating. A large portion of the makes are intrigued in using the high level Computer Numeric Control (CNC) machines for creating the assortment of items inside the recommended time to get the necessary item without any problem. In this exploration 
article, lean devices usage is engaged for guiding gearbox producing industry who is the maker of various controlling gearboxes referred to in Chennai. Explicitly the investigation was completed on positive line of stuff box producing for ceaseless improvement through kaizen and different innovations.

A meeting to generate new ideas was led with the distinctive degree of people who was liable for the entirety creation interaction to examine the different issues. At long last, it was chosen to execute the necessary lean devices to guarantee the entire interaction should be inside TAKT time and different proposals were given to get greatest use machines.

\section{Literature Review}

Indian assembling industry has witnessed great challenges in the current scenario regarding low costs, improved quality and differing items with predominant execution, Dhruv Shah et al. 2018 [25]

Lean, which thinks about that any movement which devours assets however not make an incentive for the end client is inefficient, and along these lines ought to be wiped out $[17,18]$.

At functional level lean assembling is helped out through a lot of lean procedures and steps. By executing these steps and procedures lean assembling mainly focuses to recognize and dispose of various squanders exist inside the production line or along the store network Sohal [19, 20].

Apply the fit apparatus by strategy time estimation and line balance proficiency and decrease the process duration in a truck body mechanical production system and improve effectiveness in that product offering. Additionally says that lean assembling is a business theory that ceaselessly improves the procedure include in assembling. [1-4]

Author Vinodh et al. in his paper discusses how lean is being used as an assembling worldview dependent on the basic objectives of Toyota Production System (TPS), which is focused on persistently limiting waste to expand stream [916].

Upadhye et al. [24] in their paper have confronted how the Application of VSM in a roll fabricating plant has influenced the results by finding that use of lean assembling brought about increment in quality, decline in inventory, increase in opportune conveyances, better usage of room and supplies and decrease in lead time.

Gupta et al. [23] in his paper deals with the utilization of lean assembling in a spiral tire fabricating firm and found that authoritative culture and human asset the board assume an indispensable job to deal with the change. Creators likewise found that significant reasons for high assembling cost were over-handling and unnecessary imperfections.

Singh et al., Garza-Reyes et al. and Ghosh [7, 22, 28] in their respective papers have mentioned about how the Indian assembling business runs with respect to lean execution issues yet there is scarcely any exploratory research related and focussed upon the process needed to improve in the assembling area of Indian manufacturing units. The paper was about how exact examination which will connect this hole by tending to the unmistakable issues in regards to lean usage in Indian procedure ventures and will outfit significant results for general application and forthcoming exploration. [5-6]

In the paper titled, Biodiesel from Lemon and Lemon grass oil and its impact on Engine execution and fumes emanations by S. Sundararaj and R. Dhivagar, examined about motor exhibitions. This paper was valuable to dissect the different zones where lean can be executed [26, 27].

Indeed, even in papers managing composite materials by Kaviyarasan et al, Dr. P. Prathap and T. Pridhar it is conceivable to execute lean for expanding the effectiveness and time $[8,21]$

Paper on Productivity enhancement in engine assembly using lean tools and techniques by P. Sivaraman et al discusses in detail about DMAIC approach [29].

\section{Process Flow Chart}

This paper centers around cycles of chosen gears with its order of parts and different models utilized in car vehicles. The various cycles for the chose directing stuff box with its interfacing parts are appeared in interaction stream outline for the assembling of directing stuff box through a bunch of twisting angle gears.

\section{Information Collection and Analysis}

\subsection{Current State VSM}

Different information were gathered dependent on the current situation like process duration for each cycle, set up an ideal opportunity for each activity and change-over the long run for instrument and segment. Also level of stock, accessibility of machines status and absolute number of laborers in the shop floor associated with various activities. In view of the gathered information the planning of different cycles was done to make the current status of VSM. The accompanying Figure 1 shows the present status VSM made through the current producing situation of various degrees of winding and helical slant gears. Likewise the perceptions through VSM examination are summed up and given in Table 1 .

The lean tool of kaizen was acquainted in the current technique with upgrade the efficiency by diminishing the wastages. A conversation was led with the various levees of individuals like architects, line administrators and talented works to get the different proposals for development of the efficiency. Essentially for presenting the lean devices of work normalization and line adjusting numerous thoughts were gathered from them. 
Table 1. Observations of current state VSM.

\begin{tabular}{|c|c|c|c|c|c|c|c|c|}
\hline \multirow[b]{2}{*}{ S. No } & \multirow[b]{2}{*}{ Operation Name } & \multirow[b]{2}{*}{ Machine Type } & \multirow{2}{*}{$\begin{array}{l}\text { Takt Time } \\
\text { (in mins) }\end{array}$} & \multirow{2}{*}{$\begin{array}{l}\text { No of } \\
\text { Machines / } \\
\text { Laborers Req. }\end{array}$} & \multicolumn{3}{|c|}{ Cycle Time } & \multirow{2}{*}{$\begin{array}{l}\text { Actual } \\
\text { Cycle time } \\
\text { (in mins) } \\
\end{array}$} \\
\hline & & & & & $\begin{array}{l}\text { Up Time } \\
\text { (in mins) }\end{array}$ & $\begin{array}{l}\text { Down Time } \\
\text { (in mins) }\end{array}$ & $\begin{array}{l}\text { Total Time } \\
\text { (in mins) }\end{array}$ & \\
\hline 1 & Finish Turning & CNC Turning & 15.5 & 1 & 10.2 & 2.5 & 12.7 & 12.7 \\
\hline 2 & Worm Hobbing & CNC hobbing & 15.5 & 2 & 32 & 5 & 37 & 18.5 \\
\hline 3 & Broaching & $\begin{array}{l}\text { Conventional } \\
\text { Broaching }\end{array}$ & 15.5 & 1 & 4 & 0.5 & 4.5 & 4.5 \\
\hline 4 & Deburring & Manual & 15.5 & 1 & 3 & 0.5 & 3.5 & 3.5 \\
\hline
\end{tabular}

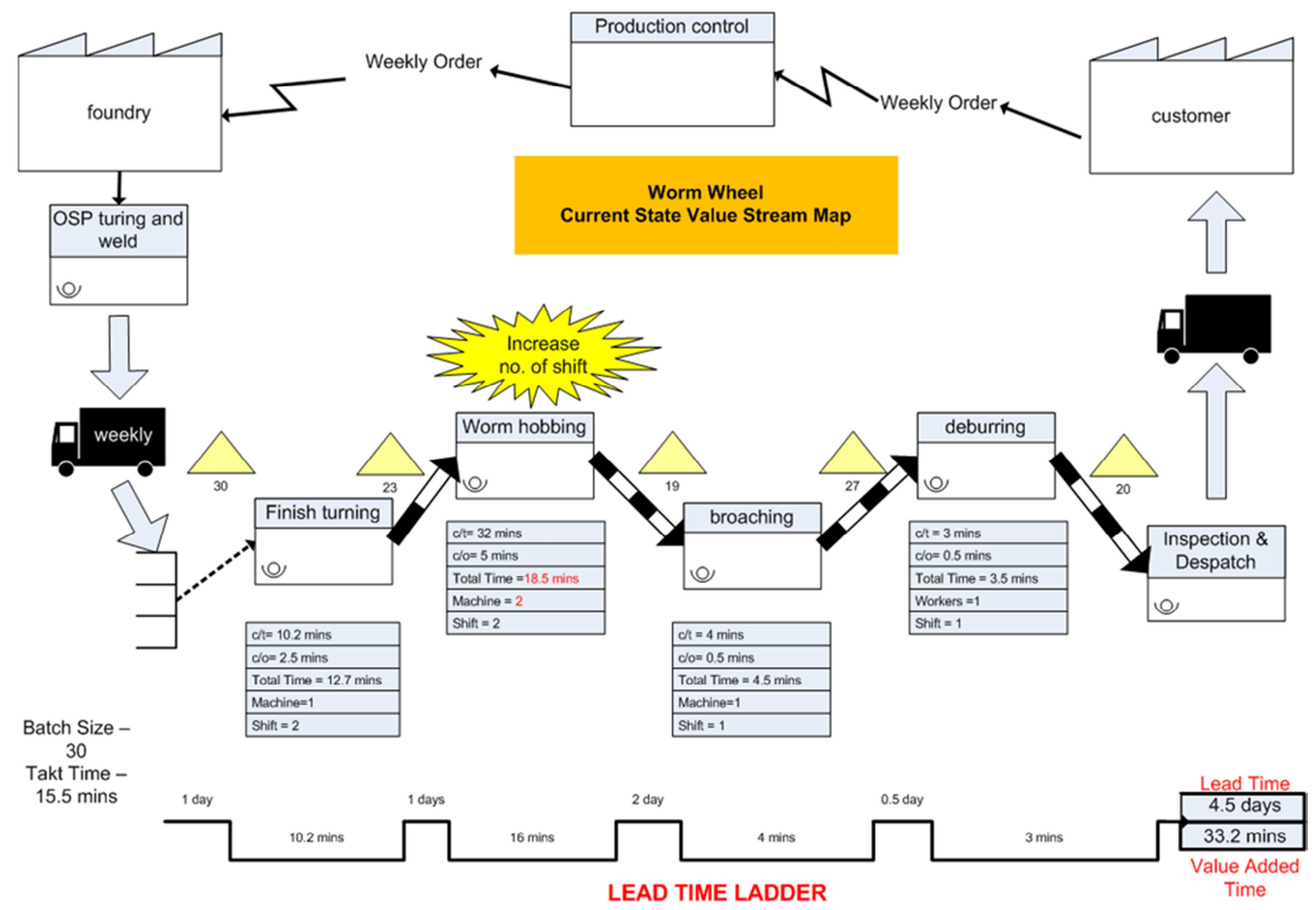

Figure 1. VSM - Current state.

From the current state of VSM, the total lead time was calculated and Takt time calculation for the manufacture of the worm wheel:

Takt Time Calculations for Worm Shaft:

Weekly Demand=350

Available Time per shift (in mins) $=450 \mathrm{mins}$

No. of shifts per day $=2$

Total Available time per day $=900$

No. of working days $=6$

Available time in a week $=5400$ mins.

Takt Time $=$ Available Time/Demand

$$
\begin{aligned}
& =5400 / 450 \\
& =15.5 \text { mins. } \\
& =21 \text { minutes. }
\end{aligned}
$$

\subsection{Non Value Added Activities}

In the chose shop floor line the cycles did in existing were examined and looked at to locate the non esteem added steps included. The proper information was too gathered to discover the burns through and lead time happening in the current interaction. In view of the gathered information a point by point depiction was made about the office accessible for producing. More throughout measure time, arrangement time and the quantity of laborers included were examined to make a future state VSM. Quantities of testing tasks have been finished through the noticed information and the path values were shown up utilizing moderate standard table. Worth added and non-esteem added ventures with Necessary Non-Value added Activity (NNVA) was assessed by the chosen following assembling measure. The required exercises were applied after make short the NVA and NNVA steps to totally destroy the NVA with limit the NNVA for achieving the client interest.

The segments were ordered as interior and outer exercises 
for figuring the specific arrangement time furthermore, again the equivalent has been arranged in to huge components like records assortment, relocation information, guideline, oversee, dispatching and so on When all is said in done the arrangement related segments are utilized to create and limit the arrangement time during assembling measure by the idea of Eliminate, Combine, Reduce and Simplify (ECRS). For building up the operational methodology with customary office the executives techniques the ECRS framework is applied. ECRS is only dispose of undesirable interaction, join the common tasks, reschedule the interaction dependent on the accessibility of machines and make things simpler by improving the whole assembling measure during the assembling of the segment. By actualizing the ECRS strategy the complete NVA need to brew adicated and the necessary yield might be achieved inside normal time to get the interest.

\subsection{Line Balancing}

Line adjusting is a lean apparatus utilized in transport line to adjust the outstanding burden between the specialists and to diminish the NVA cycle to show up the most extreme item by viably utilizing all the machines 7 . The proposed line adjusting strategy for the chose CNC shop floor is appeared in the accompanying Figure 3 with the different advances engaged with the current format. Through this proposed line adjusting strategy the labor and the machine use ought to be expanded as most extreme for accomplishing the item at right time to fulfill the need. The process duration for each work station was determined before line adjusting. The transport line has seven workstations and seven specialists. The cycle time for each station before line adjusting was determined furthermore, it was discovered that the absolute process duration for each of the seven work stations is 57 minutes.

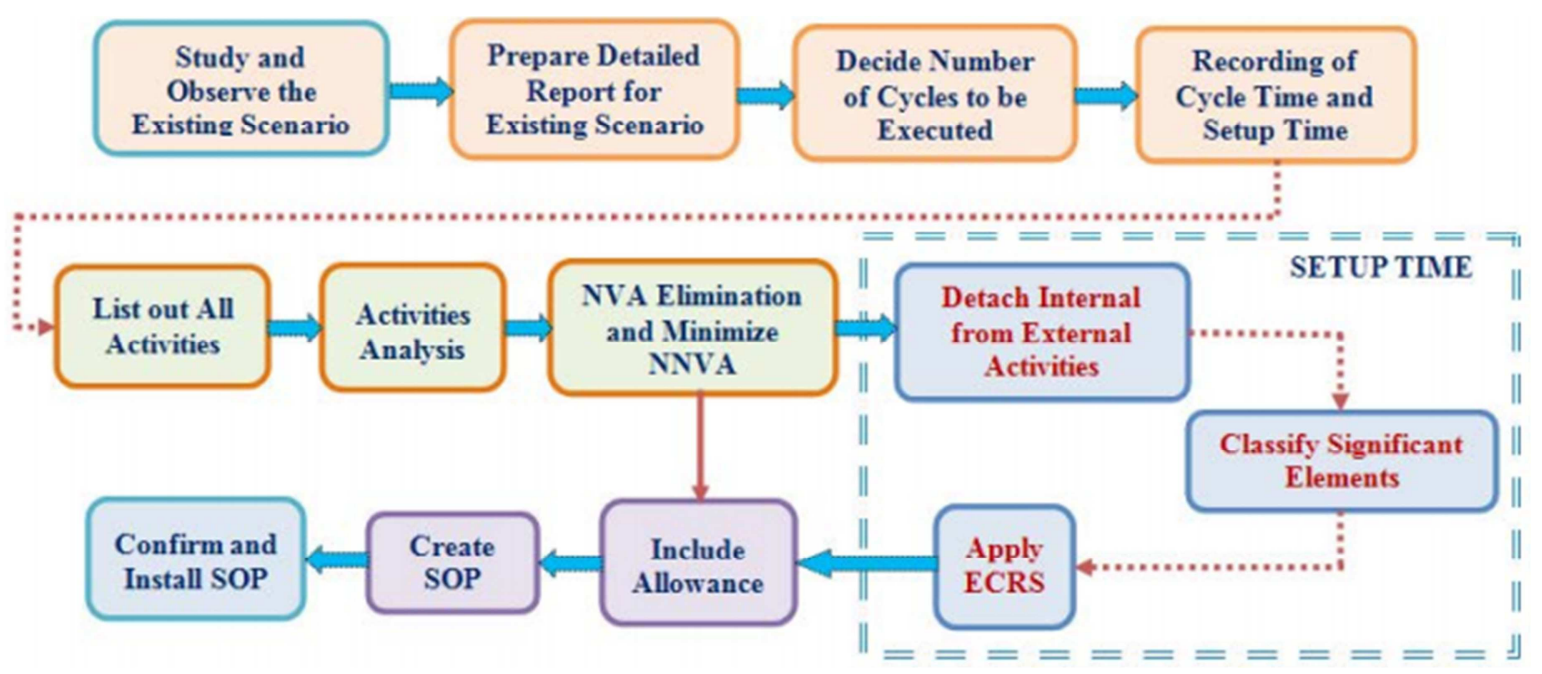

Figure 2. Methodology used.

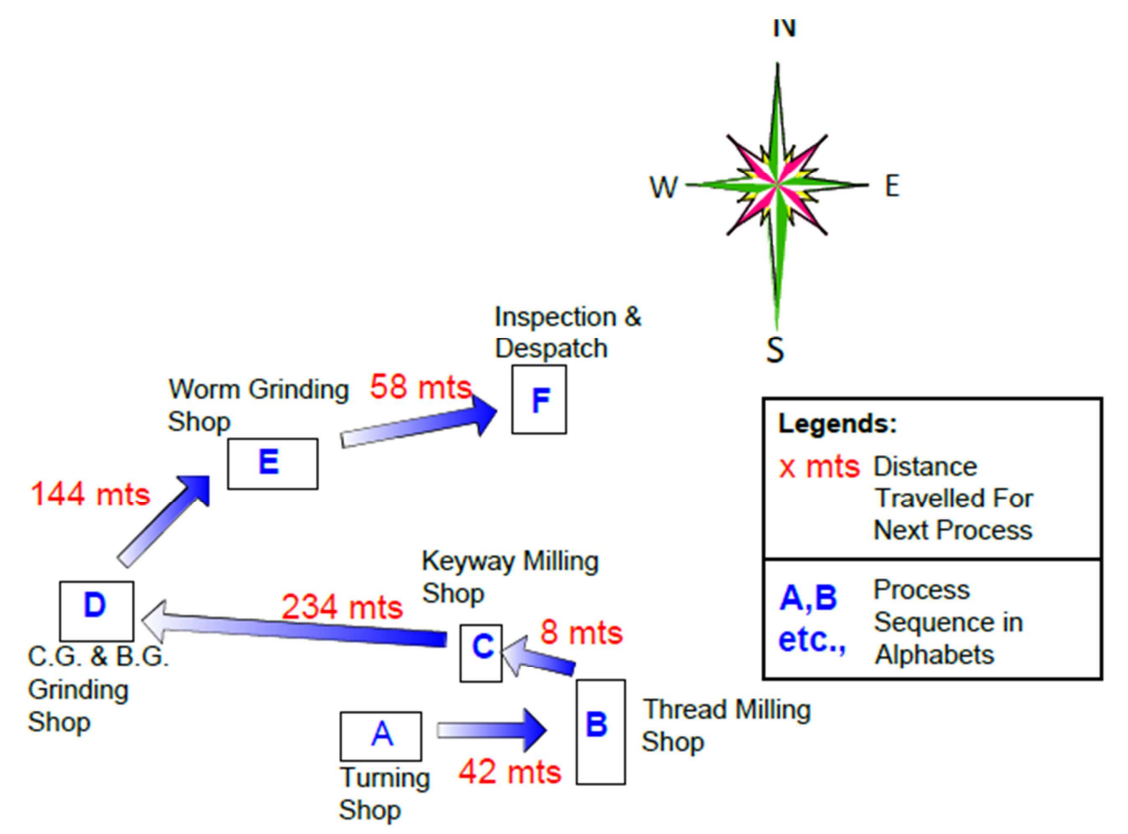

Figure 3. Process layout of worm shaft. 


\subsection{Work Standardization}

Normalization of the tasks was completed based on the characterized methodology and is appeared in the accompanying Figure 4. During the time concentrate there are three sets of cycle completed to discover the continuous taken for measure cycle and arrangement. There are about more than 160 enhancement thoughts were recommended by various level of workers during the Kaizen and the equivalent was applied during the assembling interaction to diminish the in general lead time. The exercises have been isolated as interior what's more, outer and the basic components were distinguished for both the exercises to apply ECRS for diminishing arrangement time.

Essential remittances were given for every activity to get the item with high caliber at opportune chance to achieve the request.

\section{Result and Discussion}

From the examination it was seen that the process duration was diminished by around 98 minutes and the arrangement time was around 180 minutes through normalization lean device. The correlation of cycle and set up time when the execution of lean instruments are given in the accompanying
Figure 3 In the wake of presenting the appropriate recompenses for each activity the Standard Operating Procedures (SOP) was made to do the cycle for fruition of the item. The created SOP was confirmed through appropriate channel for execution. During the cycle for an simple appraisal of the work by the specialists a reconsidered duplicate of the SOP was glued in each machine. Because of another sending of SOP it was seen that the lead time was decreased in the assembling line without influencing the required yield.

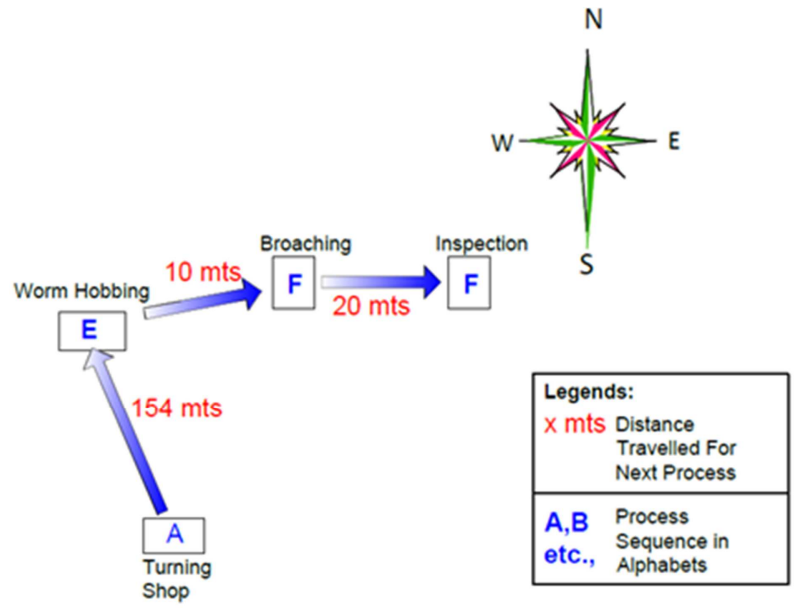

Figure 4. Process layout of worm wheel.

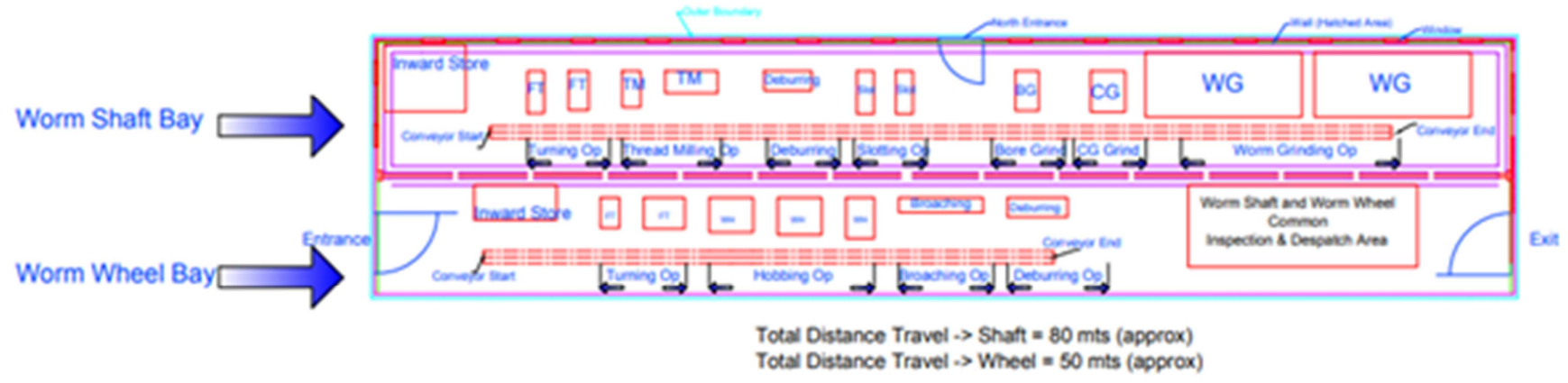

Figure 5. Process based cellular layout for worm wheel and worm shaft.

So based on Figures 3 and 4 the distance travelled by the parts within the plants is leading to a huge volume. Because of this, there are several chances where the process can go out of control and the flow cannot be maintained properly. Hence a cellular type layout can be created to streamline the production process. The main aim of cellular layout is to move the parts to be manufactured as quickly as possible, make a wide variety of similar products. The cellular layout is a collection of cells, where each cell has a specialized manufacturing process. As the part moves from one manufacturing cell to another cell, the particular manufacturing process get's completed. Using Cellular layout the process time can still be reduced for both worm shaft and worm wheel.

\section{Conclusion and Future Scope}

In light of the above examination and results the accompanying ends were drawn.
1) From the present status of VSM different huge NVA exercises were distinguished.

2) Future state VSM was made by recognizing the different progression openings.

3) Point to point format graph was ready for the current format and the equivalent was improved.

4) Workload was similarly circulated between the administrators and the vital keys were actualized.

5) It was figured out that the process duration was diminished by around 300 minutes and arrangement time was too decreased by around 180 minutes.

6) The trials directed with these exercises were determined that the use of VSM in guiding stuff box producing has come about in lessening the assembling lead time from 7 days to 5.5 days to accomplish the interest on schedule.

The examination might be proceeded with various lean apparatuses execution in various assembling businesses for constant improvement. 


\section{References}

[1] Morales Méndez JD, Rodriguez RS. "Total productive maintenance (TPM) as a tool for improving productivity: a case study of application in the bottleneck of an auto-parts machining line" Int J Adv Manuf Technol. 2017; 92 (1-4): 1013-1026.

[2] Arunagiri P, Gnanavelbabu A. "Identification of high impact lean production tools in automobile industries using weighted average method. Procedia Eng. 2014; 97: 2072-2080.

[3] Panwar A, Jain R, Rathore APS. Journal of Manufacturing Technology Management Lean Implementation in Indian Process Industries - Some Empirical Evidence Lean Implementation in Indian Process Industries - Some Empirical Evidence. Vol 26.; 2015.

[4] Kumar SS, Kumar MP. Cycle Time Reduction of a Truck Body Assembly in an Automobile Industry by Lean Principles. Procedia Mater Sci. 2014; 5: 1853-1862.

[5] Sundar R, Balaji AN, Satheesh Kumar RM. A review on lean manufacturing implementation techniques. Procedia Eng. 2014; 97: 1875-1885.

[6] Rahani AR, Al-Ashraf M. Production flow analysis through Value Stream Mapping: A lean manufacturing process case study. Procedia Eng. 2012; 41 (Iris): 1727-1734.

[7] Singh R, Gohil AM, Shah DB, Desai S. Total productive maintenance (TPM) implementation in a machine shop: A case study. Procedia Eng. 2017; 51 (NUiCONE 2012): 592599. doi: 10.1016/j.proeng.2013.01.084.

[8] Mr. B. Suresh babu, Mr. C. Boopathi, Mr. T. Pridhar, Dr. R. Srinivasan, "Production and characterization of mechanical and microstructural behaviour of friction stir welded Al6063 composites reinforced with $\mathrm{Gr} / \mathrm{B} 4 \mathrm{C} / \mathrm{SiC}$ particles", Journal of Ceramic Processing Research, ISSN 1229 - 9162, Vol. 19, No. 1, pp. 69-74 2018.

[9] Vinodh S, Gautham SG, Ramiya A. Implementing lean sigma framework in an Indian automotive valves manufacturing organisation: A case study. Prod Plan Control. 2017; 22 (7): 708-722.

[10] Vinodh S, Arvind KR, Somanaathan M. Application of value stream mapping in an Indian camshaft manufacturing organisation. J Manuf Technol Manag. 2017; 21 (7): 888-900.

[11] Ahuja IPS, Khamba JS. Strategies and success factors for overcoming challenges in TPM implementation in Indian manufacturing industry. J Qual Maint Eng. 2008; 14 (2): 123 147.

[12] Almanei M, Salonitis K, Xu Y. Lean Implementation Frameworks: The Challenges for SMEs. Procedia CIRP. 2017; 63: 750-755.

[13] Venkataraman K, Ramnath BV, Kumar VM, Elanchezhian C. Application of Value Stream Mapping for Reduction of Cycle Time in a Machining Process. Procedia Mater Sci. 2014; 6 (Icmpc): 1187-1196.
[14] Manufacturing Industry. J Ind Syst Eng. 2017; 2 (3): 180-196.

[15] Rohani JM, Zahraee SM. Production Line Analysis via Value Stream Mapping: A Lean Manufacturing Process of Color Industry. Procedia Manuf. 2015; 2 (February): 6-10.

[16] 1Krause DR, Ellram LM. Critical elements of supplier development the buying-firm perspective. Eur J Purch Supply Manag. 1997; 3 (1): 21-31.

[17] Shah R, Ward PT. Lean manufacturing: Context, practice bundles, and performance. J Oper Manag. 2003; 21 (2): 129149.

[18] 1Sohal AS. Developing a lean production organization: an Australian case study. Int J Oper Prod Manag. 1996; 16 (2): 91-102.

[19] 1 Antony J. Six Sigma vs Lean. Int J Product Perform Manag. 2011; 60 (2): 185-190.

[20] Belekoukias I, Garza -Reyes JA, Kumar V. The impact of lean methods and tools on the operational performance of manufacturing organisations. Int J Prod Res. 2014; 52 (18): 5346-5366.

[21] K Kaviyarasan, T Pridhar, B Sureshbabu, C Boopathi and $\mathrm{R}$ Srinivasan. Fabrication of $\mathrm{Al} 6061-\mathrm{Al}_{2} \mathrm{O}_{3}$ composite through liquid metallurgy technique IOP Conf. Series: Materials Science and Engineering, Volume 402, No 99 (2018).

[22] Ghosh M. Lean manufacturing performance in Indian manufacturing plants. J Manuf Technol Manag. 2012; 24 (1): 113-122.

[23] Gupta S, Jain SK. A literature review of lean manufacturing. Int J Manag Sci Eng Manag. 2013; 8 (4): 241-249.

[24] Upadhye N, Deshmukh SG, Garg S. Lean manufacturing system for medium size manufacturing enterprises: An indian case. Int J Manag Sci Eng Manag. 2010; 5 (5): 362-375.

[25] Dhruv Shah. Productivity Improvement by Implementing Lean Manufacturing Tools In Manufacturing Industry, IRJET March 2018 pp 3794-3798.

[26] R. Saravanan, "Scheduling optimization of a Flexible manufacturing system using a modified NSGA-II algorithm" Advances in Production Engineering \& Management 2014 ISSN 1854-6250, Vol. 9, No. 3, pp 139-151.

[27] S. Sundararaj, R. Dhivagar "Biodiesel from Lemon and Lemon grass oil and its effect on Engine performance and exhaust emissions" in material science engineering 2018, ISSN 1757-899X Volume 330.

[28] Dr. P. Prathap, "Performance Analysis of Abrasive Water Jet Cutting Process in Carbon Fiber Epoxy Polymer Composite", IOP Conference Series: Materials Science and Engineering, ISSN 1757-898, Proceedings 2019-12-19.

[29] P. Sivaraman, T. Nithyanandhan, S. Lakshminarasimhan et al., Productivity enhancement in engine assembly using lean tools and techniques, Materials Today: Proceedings, 33 (2020) 201-207. 